\title{
Synthetical Weather Index Insurance Product Design - A Case of Millet in Wuzhai, Shanxi
}

\author{
YueqinWang, Sijian Zhao, Qiao Zhang, Qian Nie
}

Agricultural Information Institute of Chinese Academy of Agricultural Sciences, Key Laboratory of Digital Agricultural Early-warning Technology, MOA, Beijing 100081, China

\section{农业综合天气指数保险产品设计一以山西五寨 县谷子为例}

\section{王月琴, 赵思健, 张峭, 聂谦}

中国农业科学院农业信息研究所，农业部智能化农业预警技术重点开放实验室，北京 100081， 中国

\begin{abstract}
Using the daily meteorological data from 1957 to 2015 , the time series data of millet yield from 1980 to 2015 , and the investigation and previous studies of meteorological disasters in Wuzhai County of Shanxi Province, the key meteorological disasters affecting the yield of millet at various growth phases is determined. Comparing the historical yield loss and main disasters, we construct synthetical weather indices such as rainstorm index $\mathrm{P} 1+$, freeze injury index T4-, drought index P1-, P2, P3-, P4- during key growing periods. A model for optimizing the relationship between weather indices and yield loss is proposed to quantitatively evaluate the impact of weather indices on crop yields. The synthetical weather indices insurance of millet is designed and then the premium rates and trigger values are given.
\end{abstract}

Keywords: millet; synthetical weather indice; growing phases; adverse weather; yield loss; optimal matching

\section{摘要}

本文利用山西省五寨县 1957-2015 年气象 要素日值数据、1980-2015 年谷子单产时间
序列数据以及实地调研和文献资料䇻选出 影响谷子各生长阶段产量的关键气象灾害, 然后通过历史产量损失与主要灾害的气象 指标对比分析, 构建暴雨指数 P1+、冻害指 数 T4-、干旱指数 P1-、干旱指数 P2-、干 旱指数 P3-、干旱指数 P4-共 6 个天气指数。 在建立五寨县的气象灾害和产量损失优化 关系模型的基础上，定量评估天气指数对 作物产量的影响, 并对谷子综合天气指数 产品进行设计, 计算出保险费率及指数触 发值。

关键词: 谷子; 综合天气指数; 生长期; 气象异常; 产量损失; 优化匹配

1. 引言

天气指数保险是将一个或几个气象要 素对农作物的损害程度指数化, 每个指数 都有对应的农作物产量和损益，当天气指 数对产量的影响到达一定水平, 就可获得 相应标准的赔偿, 是对气象导致的农作物 产量下跌风险进行保障的一种保险产品。 我国农业生产规模化组织程度低, 造成现 有农业保险承保理赔、勘察定损交易成本 高, 天气指数保险以客观天气条件作为赔 付依据, 能有效降低成本, 为传统农业保 险提供另一种可行的选择。随着我国农村 保险需求的不断提高, 天气指数保险已成 为农业保险多元化创新发展的重要驱动力。 
2014 年在国务院出台的《关于加快发展现 代保险服务业的若干意见》中明确提出要 鼓励探索天气指数保险等新兴产品和服务, 确立了天气指数保险的创新地位; 2016 年 “中央一号” 文件再次提出 “探索开展天 气指数保险试点”, 天气指数保险逐渐接过 了农险转型的接力棒; 2016 年农业部《关 于开展 2016 年度金融支农服务创新试点的 通知》中重点提到通过创新天气指数保险 等方式探索运用保险以及保险与其他金融 工具融合促进我国农业现代化发展的有效 模式。可以预见, 在未来, 天气指数保险 将成为我国转移气象灾害风险的重要方式。

天气指数保险客观可靠, 无需勘察定 损, 赔款及时, 避免了逆向选择和道德风 险的发生, 能够对中小农户规避风险提供 有力的保障, 被越来越多的学者和保险公 司视为发展中国家应对农业气象灾害的有 效替代方式。研究上, 国内外天气指数保 险的研究主要集中在两个方面：其一是天 气指数保险的优缺点研究, Skee 等 (1997)、 度国柱和李军 (2006)、Lisha Zhang （2008）等都指出天气指数保险具有交易 成本低、降低道德风险等优点 $[1-3]$, 度国 柱（2008）指出天气指数保险存在天气指 数难以制定和缺乏公平性的缺点, 张峭 （2008）则将 “公平性” 缺点概括为 “基 差风险”, 认为个体农户的农作物经济损失 与该地区总体损失程度有关 [4]。Barnett 和 Mahul（2007）认为基差风险来源于病 虫害等其他除天气因素以外的原因或者区 域性微气候 [5] 。其二是天气指数保险产品 设计的研究, 例如娄伟平等 (2009) 开展 了浙江省金华市柑橘低温冻害指数保险产 品的研究 [6]、吴利红 (2010) 开展了浙江 省县级水稻综合天气指数保险产品的研究 [7]、杨太明（2013）开展了安徽省宿州市 小麦综合天气指数保险产品研究 [8]、牛浩 和陈盛伟 (2015) 等开展了山东省宁阳县 玉米风雨倒伏指数保险产品的研究 [9], 等 等。在实务方面, 国外天气指数保险最早 出现在 20 世纪 90 年代, 并在世界银行等 国际组织支持下开展试点。2002 年墨西哥 开始天气指数保险试验、印度 2003 开始天
气指数保险试验、马拉维 2005 年试验天气 指数保险、埃塞俄比亚和联合国粮食计划 署 2006 年试点天气指数保险。其中, 印度 的天气指数保险做得较好, 推广面积很大, 一直受到世界银行的推荐。在我国, 天气 指数保险引进时间较短。2007 年上海安信 农业保险公司在上海地区推出了全国首个 “西瓜天气指数保险” 产品; 2009 年安徽 国元农业保险公司与世界粮食计划署在安 徽试点 “水稻种植天气指数保险”; 2011 年 中国人民保险财产保险公司在江西抚州南 丰县试点 “柑橘天气指数保险”; 2013 年中 国人民保险财产保险公司在世界银行支持 下在海南省试点 “橡胶树风灾指数保险”; 2015 年中华联合财产保险公司在北京试点 “玉米干旱天气指数保险”; 2016 年太平洋 保险公司在北京试点推出 “露地蔬菜天气 指数保险”, 等等。

天气指数保险虽在国内发展迅速, 但 基本局限于地方性试点, 未能全面铺开。 其中一个原因在于作物受灾机理十分复杂 性, 作物生长过程中往往不是受单一气象 灾害影响, 而是多重灾害的综合影响 [10], 而当前的天气指数保险研究往往是针对作 物的某一种气象要素或至多两种气象要素, 且风险测算时往往分离两种气象要素分别 测算而非综合测算, 缺乏科学性 [11]。为 此, 本文将从构建多天气指数与作物产量 损失优化匹配关系模型入手开展区域性综 合天气指数保险产品的开发研究, 并以山 西省五寨县谷子为例进行实证, 旨在为开 发综合天气指数保险提供技术支撑。

\section{2. 结果分析}

\section{1 研究区域概况}

谷子是山西省的第一大杂粮作物、第 二大粮食作物, 播种面积连续三年居全国 第一, 比重达到全国的三分之一左右, 可 见谷子在山西农业生产和农村经济发展中 的重要作用。其中, 晋西北的五寨县一带 的杂交谷子已形成一定规模, 是山西杂交 谷子优势产区。虽然, 五寨县的杂交谷子 的产量有一定规模, 但每年都要受自然灾 害 (暴雨、干旱和冻害等) 的影响, 造成 
一定量的减产, 给谷子种植户带来经济损 失。为了稳定谷子生产、大力发展特色产 业、保障广大谷子种植户收入, 亟需开展 谷子保险。为此, 本文以五寨县谷子为例, 探索与开发谷子综合性天气指数保险, 规 避谷子种植风险, 促进谷子产业发展。

\section{2 数据资料}

本文收集整理了如下三类数据:

\section{(1) 产量数据}

五寨县 1980-2015 年间的谷子单产时 间序列数据, 数据源于中国农业部县级农 村经济统计数据库;

(2) 气象数据

五寨县气象监测站自 1957-2015 年气 象要素日值数据, 具体的气象要素包括日 累计降雨量、日最低温度, 数据源于国家 气象局;

\section{(3) 谷子生长期数据}

五寨县谷子在每年 5 月 28 日到 7 月 23 日出苗到拔节, 7 月 24 日到 8 月 5 日拔节 到抽雄, 8 月 6 日到 8 月 28 日抽雄到灌浆, 8 月 29 日到 9 月 25 日灌浆到成熟。谷子生
长期数据来自五寨县农气监测站。

\section{3 研究方法}

\section{（1）总体思路}

(1)分析五寨县气象灾害历史发生状况 及谷子生产面临的风险, 篮选影响作物产 量的关键气象要素, 构建相应的天气指数; (2)利用单产去趋势模型将单产年度趋势剔 除, 剩余部分被认为是由气象灾害造成的 产量波动时序数据; (3)通过建立气象异常 与产量异常之间的优化匹配关系实现作物 产量与气象之间定量关系的识别; (4)计算 谷子期望损失率作为天气指数保险的纯费 率, 根据定量关系模型确定各指数的赔付 标准。

(2) 天气指数的选取

结合谷子相关文献和数据的分析, 统 计五寨县谷子各生长期受到的主要气象灾 害如表 1 所示, 将天气指数设计如下:

(1)暴雨指数: 五寨县偏早, 降水量较 少, 发生暴雨的次数很少, 大多发生在谷 子生长前期出苗期。将一日或连续多日有 效降雨 (日降雨量超过 $5 \mathrm{~mm}$ 为有效降雨),

\begin{tabular}{|c|c|c|c|c|}
\hline 生长期 & 日期 & 气象灾害类型 & 致灾机理 & $\begin{array}{c}\text { 是否作为参考 } \\
\text { 项 }\end{array}$ \\
\hline \multirow[t]{2}{*}{ 出苗期 } & $\begin{array}{c}5 \text { 月 } 28 \text { 日 }-7 \\
\text { 月 } 23 \text { 日 }\end{array}$ & 暴雨 & 无法出苗 & $\sqrt{ }$ \\
\hline & & 干旱 & $\begin{array}{c}\text { 不利于出苗及后期拔节 } \\
\text { 生长 }\end{array}$ & $\sqrt{ }$ \\
\hline \multirow[t]{2}{*}{ 拔节期 } & $\begin{array}{c}7 \text { 月 } 24 \text { 日-8 月 } \\
5 \text { 日 }\end{array}$ & 干旱 & $\begin{array}{c}\text { 干物质积累量急剧增 } \\
\text { 加, 谷子蒸腾和蒸发旺 } \\
\text { 盛, 需水量增大 }\end{array}$ & $\sqrt{ }$ \\
\hline & & 暴雨 & 根系腐烂 & $x$ \\
\hline \multirow[t]{2}{*}{ 抽雄期 } & $\begin{array}{c}8 \text { 月 } 6 \text { 日-8 月 } \\
28 \text { 日 }\end{array}$ & 干旱 & $\begin{array}{c}\text { 缺水会造成 “胎里旱” } \\
\text { 和 “卡脖旱”, 减少花穗 } \\
\text { 数目 }[13]\end{array}$ & $\sqrt{ }$ \\
\hline & & 暴雨 & $\begin{array}{c}\text { 造成谷穗授粉不良或发 } \\
\text { 生粘虫 }\end{array}$ & $x$ \\
\hline \multirow[t]{2}{*}{ 灌浆一成熟期 } & $\begin{array}{c}8 \text { 月 } 29 \text { 日-9月 } \\
25 \text { 日 }\end{array}$ & 干旱 & $\begin{array}{c}\text { 影响谷穗干物质积累和 } \\
\text { 谷粒品质 [14] }\end{array}$ & $\sqrt{ }$ \\
\hline & & 冻害 & $\begin{array}{l}\text { 茎叶提前调萎, 籽粒成 } \\
\text { 熟不饱满或品质变坏, } \\
\text { 甚至不能成熟 [12-13] }\end{array}$ & $\sqrt{ }$ \\
\hline
\end{tabular}


且期间单日降雨量超过 $50 \mathrm{~mm}$ 的情况, 记为 一次暴雨事件, 取其累计降雨量作为暴雨 指数, 因发生在第 1 个生长期且属于降水 异常过多, 故用 P1+表示。

(2)冻害指数: 五寨县位于山西北部, 南北环山, 中间是盆地, 容易遭受冻害的 侵袭 [12], 每年的九月份几乎都会发生不 同程度的早霜冻。根据调研结果, 若灌浆 期持续一天时间晚上低于 $2^{\circ} \mathrm{C}$ 以下, 就会发 生冻害。将日最低温度低于 $2^{\circ} \mathrm{C}$ 的温度作为 冻害指数, 因发生在第 4 个生长期且属于 温度异常过低, 用 T4-表示。

(3)干旱指数: 干旱是五寨县最严重的 自然灾害之一, 几乎年年受旱。根据调研 情况和前期对五寨县气象数据的分析, 发 现连续不降雨的情况很多, 如果按照大多 数单一气象因素研究中将干旱指数继续定 义为累计日降雨量, 则会出现很多累计降 雨量接近 $0 \mathrm{~mm}$ 的情况, 例如 2 天干旱累计 降雨量是 $0 \mathrm{~mm}, 20$ 天累计降雨量也是 $0 \mathrm{~mm}$, 无法区分干旱的程度。本文选择将干旱的 天数作为衡量干旱程度的指标, 将连续无 效降雨累计天数 (日降雨量低于 $5 \mathrm{~mm}$ 为无 效降雨) 作为干旱指数, 且连续天数超过 10 天, 记为一次干旱事件。因谷子整个生 长期都有遭受旱灾的风险且属于降水异常 过少, 故相对应的生长期的干旱指数用 P1-、 P2-、P3-、P4-表示。

\section{(3) 数据处理}

\section{(1)单产数据去趋势处理}

谷子的产量波动受众多因素的影响, 主要有两类: 一类是包括种子、化肥、病 虫害控制、农业技术水平、经营管理、政 策等在内的非自然因素, 非自然因素造成 的产量为趋势产量; 另一类是在自然气象 因素的影响下形成的气象产量。因此, 谷 子产量可以分解为趋势产量和气象产量, 即:

$$
\mathrm{Y}=Y_{t d}+Y_{w}
$$

其中, $Y$ 为谷子的实际单产 (吨/公顷), $Y_{t d}$ 为谷子的趋势单产 (吨/公顷), $Y_{w}$ 为谷 子的气象单产 (吨/公顷)。对 1980-2015 年间五寨县的单产数据采用直线滑动平均 法进行去趋势处理。直线滑动平均法将产
量的时间序列在某个阶段的变化视为线性 函数, 函数呈一直线。随着阶段的连续滑 动, 直线不断变化位置, 后延滑动, 从而 反映产量历史演变趋势变化。依次求取各 阶段内的直线回归模型, 而每个时间点上 各直线滑动回归模拟值的平均, 即为其趋 势产量。这种模拟方法的优点在于不必主 观假定或判断产量历史演变的曲线类型, 也不损失样本序列的长度, 是一种比较好 的趋势拟合方法。直线滑动平均法去趋势 的效果取决于滑动步长 $\mathrm{k}$ 的取值大小。若 $\mathrm{k}$ 太小, 趋势产量会比较接近于实际产量, 去除趋势的效果不明显, 只有当 $\mathrm{k}$ 足够大 时, 趋势产量才能消除短期周期波动的影 响。从图 1 中可以看出, 2009 年以前, 五 寨县谷子产量相对稳定。2008 年开始, 政 府开始从张家口地区引入杂交谷子系列, 并在五寨县范围内大力推广, 造成杂交谷 子的种植面积迅速增加, 再加上杂交谷子 的高产品种优势, 2009 年以后谷子的产量 出现急剧猛增的现象。由于存在品种的突 然变化, 本文对谷子的单产数据采用分段 去趋势的方法, 2009 年前给定 $\mathrm{k}$ 的范围为 6-14, 2009 年以后由于数据量太少, 为减 少相邻年份之间产量产生巨大的波动, $\mathrm{k}$ 的 范围需要减少, 本文给定范围的为 4-6, 步 长间距为 1 。最终得到五寨县的趋势产量 $Y_{t d}$ 如图 1 所示。

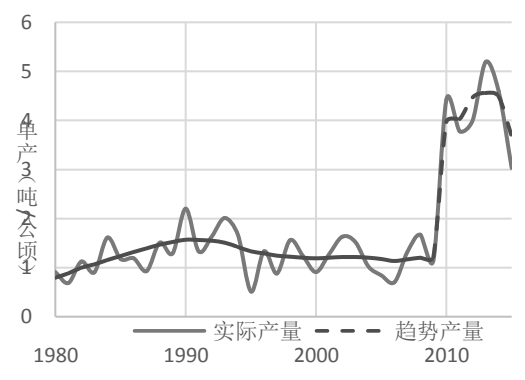

图 1 五寨县谷子单产趋势

\section{(2)天气指数归一化处理}

为了消除不同类天气指数间量纲不同 的影响, 需要对天气指数的数据进行归一 化处理, 即:

$$
\overline{\mathrm{d}} w_{g, t}=\frac{d w_{g, t}-\min \llbracket\left(d w_{g}\right)}{\max \left(d w_{g}\right)-\min \left(d w_{g}\right)}
$$


其中, $d w_{g, t}$ 表示第 $g$ 种天气指数第 $t$ 年 的天气指数值, $\bar{d} w_{g, t}$ 表示第 $g$ 种天气指数 第 $t$ 年的归一化值, $\max \left(d w_{g}\right)$ 表示该天气指 数的历史最大值, $\min \left(d w_{g}\right)$ 表示该天气指 数的历史最小值。天气指数归一化处理以 后，数值范围在 0-1 之间。利用上述方法 将五寨县的气象数据进行归一化处理。

(4) 气象异常与产量损失优化匹配关系模 型

\section{(1)单产波动率}

谷子的实际产量围绕趋势产量上下波 动, 产量波动的影响因素大致归结为社会 因素等非自然因素和气象因素, 若出现利 于作物生长的条件 (技术进步、品种改善 等), 实际产量高于趋势产量; 若出现不利 于作物生长的条件 (战争、气象灾害等), 实际产量低于趋势产量, 其中气象灾害对 作物产量波动的影响最大。去趋势后为反 映气象对产量造成的波动影响, 可用单产 波动率来衡量, 所以单产波动率可具体表 达如下:

$$
V_{y_{t, w}}=\frac{y_{t, w}}{y_{t, t d}}=\frac{y_{t}-y_{t, t d}}{y_{t, t d}}
$$

其中, $V_{y_{t, w}}$ 表示单产波动率, $y_{t, w}$ 表示气象 单产 (吨/公顷), $y_{t}$ 表示实际单产 (吨/公 顷), $y_{t, t d}$ 表示趋势单产 (吨/公顷), $\mathrm{t}$ 表示 年序。在趋势单产的基础上, 计算五寨县 谷子的单产波动率, 正值表示增产, 负值 表示减产, 结果如图 2 所示。从图中可以 看出 1990 年五寨县的单产增产率最大, 达 到了 $40 \%$ 左右; 1995 年单产减产率最大, 达到了 $61 \%$ 左右。

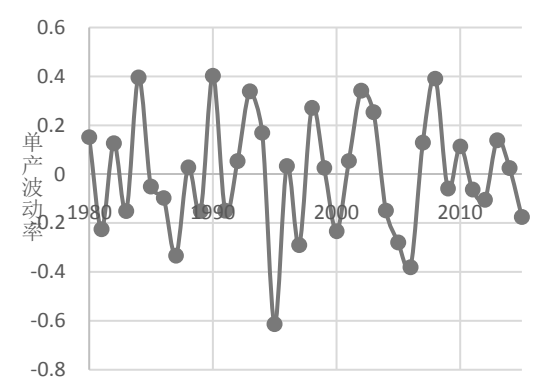

图 2 五寨县谷子单产波动率

\section{(2)单产损失率}

气象灾害的实质是某种气象因素发生 异常, 所谓异常指的是偏离正常的范围, 偏离的程度越大, 气象灾害的灾害程度越大, 理应造成的谷子单产损失越大。从历史上 看, 应该存在一个最高的增产率, 该增产 率表明在外界条件最适宜的条件下, 所能 达到的最高相对潜力增产率, 其他低于它 的产量都是发生了减产的情况。故谷子的 单产损失率通过判断单产波动率偏离历史 最好增产率 (也就是所谓的最高相对潜力 增产率) 的程度来识别, 具体表达如下:

$$
d y_{t}=\max \left(\mathrm{V} y_{t}\right)-\mathrm{V} y_{t}(4)
$$

其中, $d y_{t}$ 表示谷子第 $t$ 年的单产损失 率, $\mathrm{V} y_{t}$ 表示谷子第 $t$ 年的单产波动率, $\max \left(\mathrm{V} y_{t}\right)$ 表示谷子历史上最高潜力增产率。 在五寨县单产波动率的基础上, 获得最高 潜力增产率, 计算五寨县谷子单产相对于 最高潜力增产率后的单产损失率, 结果如 图 3 所示。从图中看出 1990 年达到了最高 相对潜力增产率 40\%, 则图 3 中 1990 年五 寨县谷子没有损失, 单产损失率为 $0 \%$, 其 他年份的产量相对于 1990 年来说都是发生 不同程度的减产。

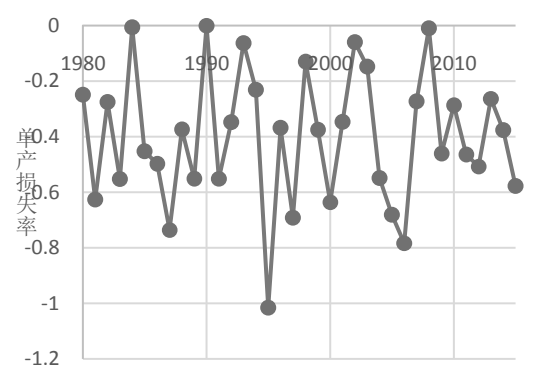

图 3 五寨县单产损失率

(2)气象异常与产量损失关系模型

在气象灾害指数上增设一个阈值, 超 出该阈值的极端异常才可能诱发气象灾害, 才可能导致谷子单产损失。不同类型、不 同地域的气象要素阈值有所差异, 不同农 作物因脆弱性不同对应的气象阈值也不尽 相同, 所以在建模时通过不断微调气象要 素阈值来不断匹配气象异常与产量损失之 间线性关系，本文中给定阈值范围为 $0.1-$ 0.9 , 步长间距为 0.1 。本文将气象要素和 
产量损失之间的关系假定为线性模型, 是 基于以下假定和考虑: 线性模型的拟合方 法较为简单; 每种气象灾害对作物的影响 是累计相加影响; 天气指数保险是一种区 域指数保险, 解决的是天气给农作物带来 的系统性风险, 故对一个区域来说出现绝 产的可能性较低。故各气象要素异常值与 产量损失之间的关系模型即:

$f_{o p}\left(d y_{t}, d w_{g, t}\right)$

$=\left\{\begin{array}{l}d y=a_{0}+a_{1} d w_{1}+\cdots+a_{g} d w_{g} \\ d w_{g}=\left\{\begin{array}{cc}d w_{g}^{o r} \text { if } d w_{g}^{o r} \geq S_{w_{g}} \\ 0 & \text { ifd } d w_{g}^{o r}<S_{w_{g}}\end{array}\right.\end{array}\right.$

其中, $f_{o p}\left(d y_{t}, d w_{g, t}\right)$ 表示气象异常与 产量损失的最优线性匹配关系, $d y_{t}$ 表示第 $\mathrm{t}$ 年谷子的单产损失率, $d w_{g, t}$ 表示的是第 $\mathrm{g}$ 种天气指数第 $\mathrm{t}$ 年超过阈值的异常的天气指 数值, $d W_{g}$ or 表示第 $\mathrm{g}$ 种天气指数的归一化 偏离值, $S_{W_{g}}$ 表示该天气指数的异常判断阈 值, $a_{g}$ 表示线性回归系数。由于不同步长 选择, 会对最终模型的拟合产生较大的影 响。在此次建立的气象异常与产量损失的 模型中, 先根据经验和文献给出单产去趋 势的步长范围, 得到每个步长下的趋势单 产, 进而得到单产波动率和单产损失率, 结合气象要素阈值范围进行不断的拟合, 通过寻找最大调整 $R^{2}$ 值找出最优匹配关系, 反向找到一个最优的步长, 使得气象异常 能与产量损失达到最优匹配。通过对不同 步长下, 最优模型的拟合优度 $R^{2}$ 比较, 从 而判断出最佳单产直线滑动去趋势步长 $\mathrm{k}$ 和每个天气指数的阈值。采用优化匹配的 方法建立五寨县谷子 1980-2015 年气象异 常与产量损失之间的关系模型，最终得到 天气指数与产量损失之间的最优关系模型, 具体表达如下:

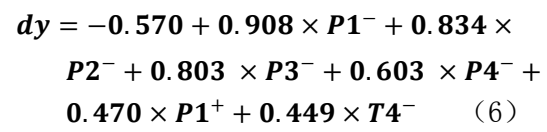

其中, 最优拟合优度 $\boldsymbol{R}^{2}=0.88$, 最优步 长 $\mathrm{K}=13$ 。干旱指数 $\boldsymbol{P} \mathbf{1}^{-}$的异常阈值为 19 天, 干旱指数 $\boldsymbol{P 2}-$ 的异常阈值为 16 天, 干旱指 数 $\boldsymbol{P 3}{ }^{-}$的异常阈值为 17 天, 干旱指数 $\boldsymbol{P 4}^{-}$
的异常阈值为 27 天, 暴雨指数 $\boldsymbol{P} \mathbf{1}^{+}$的异常 阈值为 $73.6 \mathrm{~mm}$, 冻害指数 $\boldsymbol{T 4}^{-}$的异常阈值 为 $4.4^{\circ} \mathrm{C}$ 。

\section{3. 产品开发设计}

\section{1 保险金额}

谷子天气指数保险仍然以保障农民成 本为目的, 结合前期调研情况, 每亩保险 金额参照谷子生长期内所发生的直接物化 成本 400 元。

\section{2 保险费率及保费}

农业保险产品设计的核心是纯费率的 计算, 本文用单产分布模型法厘定费率。 单产分布模型法分为参数法和非参数法, 因国内缺少适宜的研究环境和数据的非参 数不吻合性, 本文采用参数法估计模型。 根据保险学损失期望理论, 纯费率应该等 于期望损失值与实际单产之比, 即期望损 失率。利用上述天气指数和产量损失之间 的关系, 得到谷子综合天气指数的纯保险 费率为:

$$
\mathbf{R}=\mathbf{E}(\operatorname{Loss})=\sum_{t=1}^{n}\left(d_{y_{t}} \times P_{t}\right)=a_{0}+
$$

a1E ( dw1 ) +...tagE ( dwg )

$\mathrm{R}$ 表示纯费率, Loss 表示造成的损失, $\boldsymbol{d y} \boldsymbol{y}_{\boldsymbol{t}}$ 表示单产损失率, $\boldsymbol{P}_{\boldsymbol{t}}$ 表示该损失发生的 概率。在国内外研究的基础上, 选取常用 的正态分布、Logistic 分布、Beta 分布、 Gamma 分布、Johonson 分布、Weibu11 分布、 Gen-Logistic 分布和 Wakyby 分布等分布模 型, 利用 Easyfit 软件对各天气指数进行 了概率分布拟合, 通过 KS 检验、 $\mathrm{AD}$ 检验和 卡方检验来确定最优分布, 最优分布结果 统计如表 2 , 最优分布概率密度表达如表 3 。

根据上述天气指数最优概率分布, 求 出五寨县谷子综合天气指数保险的纯费率 为 $9.77 \%$ 。若加上 $30 \%$ 的经营管理费, 实际 费率大约为 $13.97 \%$, 农民每亩需要缴纳保 费为 55.88 元。从天气指数保险的机理上 来看, 天气指数保险是区域指数保险的一 类, 五寨县地区按照统一的天气指数进行 赔付, 一旦触发指数, 全县谷子种植户都 
表 2. 天气指数最优概率分布检验

\begin{tabular}{|c|c|c|c|c|c|c|c|}
\hline \multicolumn{8}{|c|}{ Goodness of Fit - Summary } \\
\hline \multirow{3}{*}{$\begin{array}{c}\# \\
\text { Statistic }\end{array}$} & \multirow{3}{*}{$\underline{\text { Distribution }}$} & \multicolumn{2}{|c|}{$\underline{\text { Kolmogorov }}$} & \multicolumn{2}{|c|}{ Anderson } & \multirow{2}{*}{\multicolumn{2}{|c|}{$\underline{\text { Chi-Squared }}$}} \\
\hline & & \multicolumn{2}{|c|}{$\underline{\text { Smirnov }}$} & \multicolumn{2}{|c|}{$\underline{\text { Darling }}$} & & \\
\hline & & Statistic & Rank & Statistic & Rank & Statistic & Rank \\
\hline P1- & Wakeby & 0.06995 & 1 & 0.28057 & 1 & 2.2273 & 1 \\
\hline P2- & $\underline{\text { Johnson SB }}$ & 0.43179 & 1 & 10.568 & 3 & 11.55 & 1 \\
\hline P3- & $\underline{\text { Normal }}$ & 0.39817 & 2 & 8.1485 & 3 & 22.514 & 2 \\
\hline P4- & $\underline{\text { Wakeby }}$ & 0.11124 & 1 & 0.70904 & 1 & 3.5143 & 5 \\
\hline $\mathrm{P} 1+$ & $\underline{\text { Normal }}$ & 0.44305 & 1 & 15.55 & 4 & 31.603 & 2 \\
\hline T4- & $\underline{\text { Johnson SB }}$ & 0.06805 & 1 & 0.36316 & 2 & 4.6764 & 3 \\
\hline
\end{tabular}

\section{表 3. 天气指数最优概率分布函数及分布图}

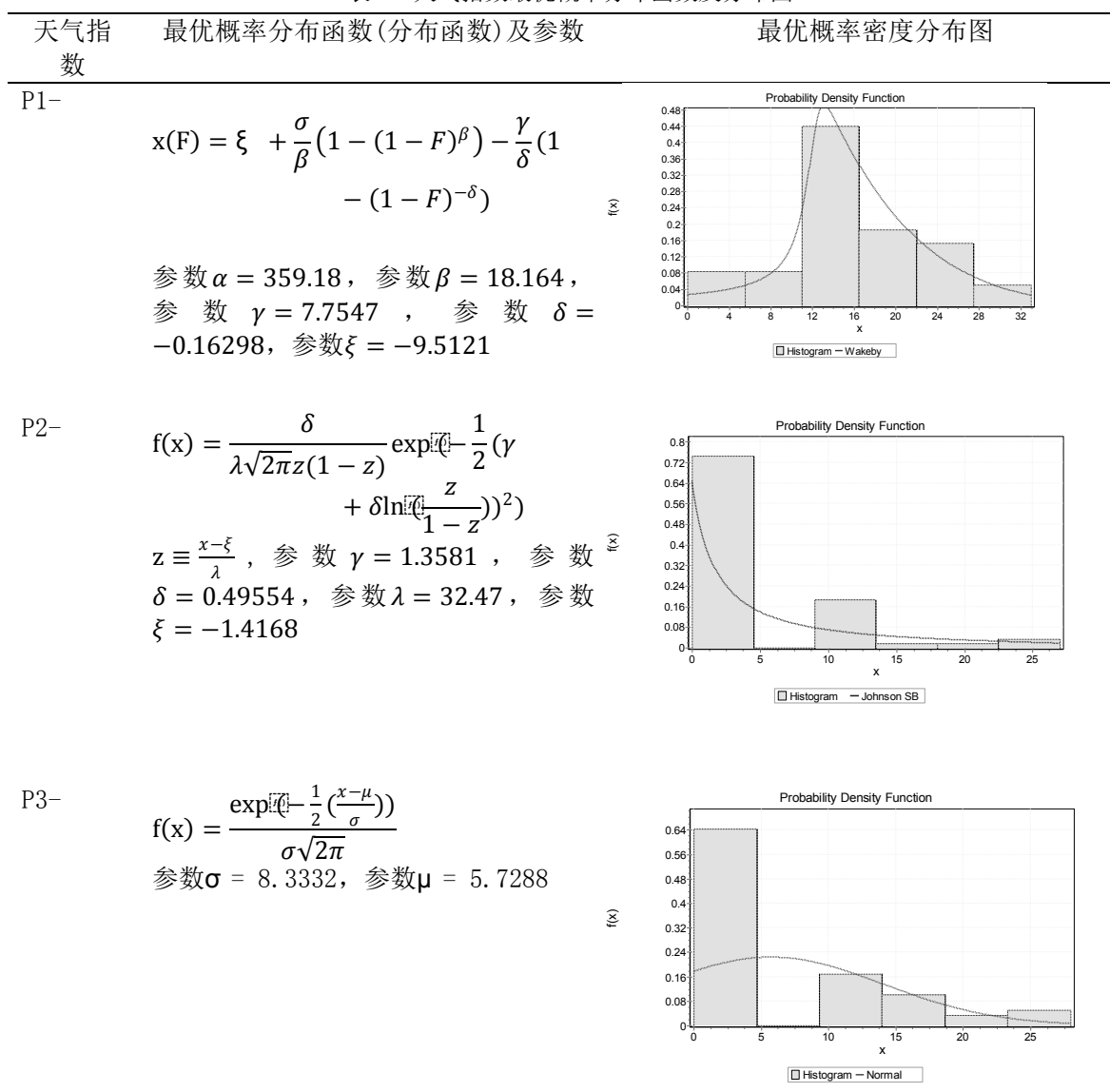


$\mathrm{P} 4-$

$$
\begin{aligned}
& \mathrm{x}(\mathrm{F})=\xi+\frac{\sigma}{\beta}\left(1-(1-F)^{\beta}\right) \\
& \quad-\frac{\gamma}{\delta}\left(1-(1-F)^{-\delta}\right) \\
& \text { 参数 } \alpha=194.31, \text { 参数 } \beta=12.065, \quad \overline{\mathrm{x}} \\
& \text { 参数 } \gamma=5.8634, \text { 参数 } \delta=0.20441, \\
& \text { 参数 } \xi=-6.802
\end{aligned}
$$

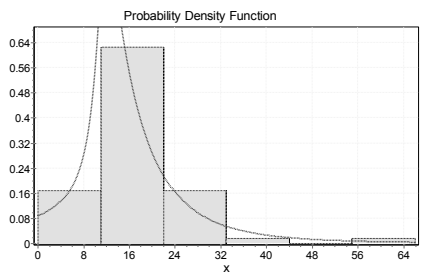

$\mathrm{P} 1+$

$$
\begin{aligned}
& \mathrm{f}(\mathrm{x})=\frac{\exp \left(1-\frac{1}{2}\left(\frac{x-\mu}{\sigma}\right)\right)}{\sigma \sqrt{2 \pi}} \\
& \text { 参数 } \sigma=13.71, \text { 参数 } \mu=4.5203
\end{aligned}
$$

T4-

$$
\begin{aligned}
& \mathrm{f}(\mathrm{x})=\frac{\delta}{\lambda \sqrt{2 \pi} z(1-z)} \exp \left(-\frac{1}{2}(\gamma\right. \\
& \left.\left.+\delta \ln \left(\frac{z}{1-z}\right)\right)^{2}\right) \\
& \mathrm{z} \equiv \frac{x-\xi}{\lambda} \text {, 参 数 } \gamma=0.06912 \text {, 参 数 } \\
& \delta=0.60435 \text {, 参数 } \lambda=6.5005 \text {, 参数 } \\
& \xi=-0.45223
\end{aligned}
$$

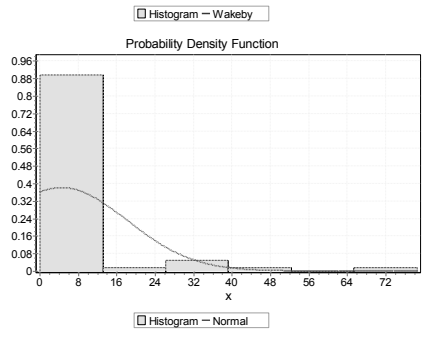

Probability Density Function

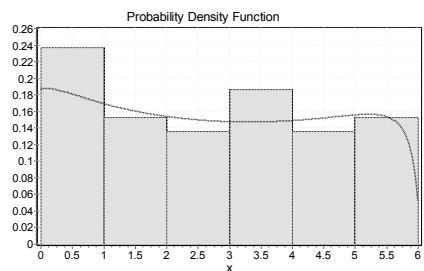

पHistogram - Johnson SB

\begin{abstract}
将得到赔偿, 并且综合天气指数涵盖的风险
对应的产量损失, 作为保险责任的上限, 以

\begin{tabular}{|c|c|c|c|c|c|}
\hline 天气指数 & & 保险期间 & 触发值 & $\begin{array}{c}\text { 单位赔付 } \\
\text { (元/ } \\
\text { 亩・mm } \\
\text { 或天 } \\
\left.\text { 或 }{ }^{\circ} \mathrm{C}\right)\end{array}$ & $\begin{array}{c}\text { 最高赔付 } \\
\text { 额（元/ } \\
\text { 亩） }\end{array}$ \\
\hline 暴雨指数 (mm) & 出苗期 P1+ & 5 月 28 日 -7 月 23 日 & 73.6 & 0.90 & 160 \\
\hline \multirow{4}{*}{ 干旱指数 (天) } & 出苗期 P1- & 5 月 28 日 -7 月 23 日 & 19 & 4.00 & 160 \\
\hline & 拔节期 P2- & 7 月 24 日 -8 月 5 日 & 16 & 6.45 & 200 \\
\hline & 抽雄期 P3- & 8 月 6 日 -8 月 28 日 & 17 & 8 & 280 \\
\hline & $\begin{array}{l}\text { 灌浆成熟期 } \\
\text { P4- }\end{array}$ & 8 月 29 日 -9 月 25 日 & 27 & 5.63 & 400 \\
\hline 冻害指数 $\left({ }^{\circ} \mathrm{C}\right)$ & $\begin{array}{l}\text { 灌浆成熟期 } \\
\text { T4+ }\end{array}$ & 8 月 29 日 -9 月 25 日 & -2.4 & 8.26 & 400 \\
\hline
\end{tabular}
较多, 这些因素的存在导致天气指数保险的 费率较高。在实践过程中需要与政府部门的 阈值为起赔点, 可以确定各个天气指数的赔 付依据。从关系模型中得到谷子天气指数保 补贴措施紧密结合, 以提高农户的参保率。

\section{3 赔付标准}

本文将各个天气指数的历史最大异常值 险的赔付依据如表 4 所示, 其中降雨量、温 度以气象部门发布的谷子所在区域 (五寨县) 的气象数据为准。根据谷子生长机理和每个
\end{abstract}

表 4. 谷子天气指数保险赔付依据 
生长阶段对谷子最终产量的影响程度, 约定 每个生长期累计最高赔偿额所占的比重分别 是 $40 \%$ 、 $50 \%$ 、 $70 \%$ 和 $100 \%$ 。当五寨县的谷子 在出苗期、拔节期、抽雄期和灌浆至成熟期 的 4 个生长期, 相对应生长期的天气指数 (暴雨、干旱、冻害) 达到保险合同约定的 当期触发值时, 保险公司依照约定负责赔偿 谷子的损失。以表中干旱指数 P1-为例, 根 据上述关系模型求出历史最大异常值对应的 天气指数为 59 天, 当承保区域 (五寨县) 的 干旱天数累计超过 19 天时, 干旱指数触发, 单位赔付额为 4 元/亩 -天。具体的赔付计算 方式如下:

每一生长期内每种气象类别的赔偿金额 $=$ (当期约定触发量与当期实际值之差值) $\times$ 当期约定单位赔偿额 $\times$ 投保亩数 (8)

每个生长期总赔偿金额 $=$ 每种气象类别 当期赔偿金额之和 (9)

需要注意的是, 每个生长期的所有气象 灾害的累计赔款均以每个生长期约定的最高 赔偿金额为限。另外, 整个生长阶段即 4 个 生长期的总赔偿金额不超过总保额 400 元。

\section{4. 结论}

本文选择试点地区山西五寨县开展谷子 的综合天气指数保险研究, 针对影响谷子产 量的暴雨、干旱和冻害气象灾害设计天气指 数, 然后构建气象灾害和产量之间的优化关

\section{参考文献}

[1] Skees J.R., Black J.R. and Barnett B.J. Designing and Rating an Area Yield Crop Insurance Contract. American Journal of Agricultural Economics.1997, 79:430-438.

[2] 度国柱,李军.农业保险问题探讨[M]. 北京: 中国人民大学出版社,2006.

[3] Zhang L H. Assessing the Demand for Weather Index Insurance in Shandong Province, China. Lexington, Kentucky: University of Kentucky, 2008.

[4] 度国柱, 张峭. 气象指数保险进入安徽 “试验田”.中国财经报, 2008.

[5] Barry J. B, Olivier M. Weather Index Insurance for Agriculture and Rural Areas in Lower Income Countries. American Journal of Agricultural Economics, 2007, 89(5): 1241-1247.

[6] 娄伟平,吴利红等.柑桔农业气象灾害风险 评估及农业保险产品设计. 自然资源学 报,2009,(6):1030-1040.
系模型, 定量评估天气指数对作物产量的影 响, 最后确定了谷子综合天气指数保险的触 发值和费率。本文具有如下特色: (1) 保障 作物关键生长期的气象灾害, 使得谷子天气 指数保险的设计更加精细化、准确化, 更加 符合天气指数的原理, 且农户每个生长期受 到灾害后即可得到补偿, 有利于继续生产。

（2）构建影响作物生长期的综合天气指数。 在以往的研究中, 对作物天气指数保险的研 究往往会局限于单一气象灾害, 忽略了作物 减产损失往往是由于生长期内受到多种气象 灾害的综合影响。(3) 考虑到气象灾害是气 象因素异常的原理, 提出气象灾害指数极端 异常值与产量损失之间的优化匹配关系, 不 仅能够再现气象灾害对产量的真正影响, 也 为评价气象因素风险提供了思路。本文在研 究过程中还存在一些不足: (1) 由于五寨县 气象站点在乡镇一级没有完全覆盖, 数据质 量也不是很好, 设计时只能采用县级气象站 的数据, 其采集地点与参保地块之间的环境 差异, 是否会产生系统误差以及如何控制基 差风险, 这将是下一步研究需要解决的主要 问题。(2) 各天气指数对作物产量损失的影 响是否存在交叉影响, 气象异常与产量之间 是否存在其他相关关系, 有待进一步探讨。

[7] 吴利红,娄伟平, 姚益平, 毛裕定, 苏高利. 水 稻农业气象指数保险产品设计-—以浙 江省为例. 中国农业科学,2010,(23):49424950.

[8] 杨太明,刘布春, 孙喜波, 等. 安徽省冬小 麦种植保险天气指数设计与应用. 中国 农业气象,2013(2):229-235.

[9] 牛浩,陈盛伟.玉米风雨倒伏指数保险产品 设计研究——以山东省宁阳县为例. 农业 技术经济,2015,(12):99-108.

[10] Guo S J. The meteorological disaster risk assessment based on the diffusion mechanism. Journal of Risk Analysis and Crisis Response, 2012, 2(2): 124-130.

[11] Zhao S J, Zhang Q. Risk Assessment of Crops Induced by Flood in the Three Northeastern Provinces of China on Small Space-and-Time Scales; Journal of Risk Analysis and Crisis Response, 2012, 2(3): 201-208.

[12] 张友贵. 山西省北 (中) 部作物冷害的初 步研究.山西气象,2002,(3):15-18. 
[13] 岳海.不同生态环境和不同栽培管理措施 对谷子品质影响研究.山西: 山西农业大 学, 2005 .

[14] 姜净卫,刘孟雨,董宝娣. 谷子及杂交种的 水分利用效率以及节水技术研究思考.节
水灌溉,2014,(10):63-70.

[15] 彭爱国,彭豆豆."张杂谷"生育期的农业气 象条件.农业气象,2002,(20):117-118. 